\title{
FLY BORNE DISEASES IN ANIMALS
}

${ }^{1}$ Carlos Ramón Bautista-Garfias, ${ }^{1}$ Gloria Sarahi Castañeda-Ramirez, ${ }^{2}$ Juan Felipe de Jesús Torres-Acosta, ${ }^{1}$ Elizabeth Salinas-Estrella, ${ }^{3,4}$ Muhammad Moshin and 'Liliana Aguilar-Marcelino

${ }^{1}$ Centro Nacional de Investigación Disciplinaria en Salud Animal e Inocuidad, INIFAP, Km 11 Carretera Federal Cuernavaca-Cuautla, No. 8534, Col. Progreso, Jiutepec, Morelos, C.P. 62550, México

${ }^{2}$ Facultad de Medicina Veterinaria y Zootecnia, Universidad Autónoma de Yucatán, Km 15.5 Carretera Mérida-Xmatkuil, CP 97100 Mérida, Yucatán, Mexico

${ }^{3}$ College of Life Science and College of Animal Sciences (College of Bee Science), Fujian Agriculture and Forestry

University, Fuzhou, China

${ }^{4}$ Department of Parasitology, University of Agriculture, Faisalabad, Pakistan

*Corresponding author: aguilar.liliana@inifap.gob.mx

\section{INTRODUCTION}

In the Animal Kingdom, arthropods are organisms with external skeletons, a segmented body, and jointed legs, such as lobsters, spiders, centipedes, and insects. The segments can be fused or grouped into body regions and the appendages can be exaggerated, modified or missing. It has been estimated that there are between one and ten million species of arthropods (they constitute $85 \%$ of animal species) and are found practically in all habitats on the planet, so it is not surprising that many species are parasites on humans and farm animals (Bautista Garfias 2016).

Some arthropods, including flies, can also transmit different pathogens, such as fungi, bacteria, viruses and parasites to domestic animals and humans (Rodhain 2015). The relationship between environment, pathogens, arthropod vectors and hosts is essentially dynamic, which means that it constantly changes. This must be kept in mind when we refer to the global climate change and the unexpected outbreaks of known and unknown diseases, as it is the case of the COVID-19.

\section{Flies as disease vectors}

As previously indicated, flies (Insecta: Diptera) are able to transmit directly or indirectly pathogenic agents to farm animals, causing considerable economic losses. There are many families and species belonging to the Class Diptera, however, only a few genera and species such as: Musca domestica, Glossina spp., Stomoxys calcitrans and Haematobia irritans, Tabanus sp., which transmit parasites to farm animals, have been considered in this chapter. In this context, the comparative size of four different hematophagous flies (Tabanus spp., Glossina spp., Stomoxys calcitrans, and Haematobia irritans) has been shown in Fig. 1.

\section{Musca domestica (house fly) (Diptera: Muscidae)}

The house fly, Musca domestica, is a cosmopolitan insect, commonly associated with farm buildings destined to house poultry, pigs, sheep, goats, horses and cattle. It is also abundant in human settlements where the garbage produced by humans is left on the surface of the soil. House flies are medium-sized Diptera, with their body length ranges from five to $12 \mathrm{~mm}$, when they are adult. Musca domestica (Fig. 2) is a successful insect pest, associated to humans and domesticated animals and found all over the world. This insect transmits more than 100 different disease causing pathogens, including parasites, to humans and animals (Mehlhorn 2015; Issa 2019). Flies feed on a variety of organic materials originated from residues that could be present in the garbage or animal excreta. Solid food is first converted into a liquid (liquefied) with the saliva of flies and then they ingest the liquified material through the mouthparts that allow them to lick and suck. When the ambient temperature is between 35 and $40^{\circ} \mathrm{C}$, the complete life cycle takes between 10 and 14 days (Bautista Garfias 2016), as shown in Fig. 3.

The parasite genera that have been isolated from houseflies include Ascaris, Entamoeba, Ancylostoma, Necator, Trichuris, Strongyloides, Metastrongylus, Haematopinus (an insect), Cryptosporidium, Giardia, Enterobius, Taenia, Hymenolepis (Khamesipour et al. 2018) and Habronema (Buzzell et al. 2011).

\section{Glossina spp. (tsetse fly) (Diptera: Glossinidae)}

All species of the genus Glossina are hematophagous. There are 23 species and eight subspecies in the Glossina genus (Rogers et al. 1994). Adults (Fig. 4) range in length from six to $15 \mathrm{~mm}$. Reproduction is viviparous through a process known as notrophic viviparity, in which the egg transforms into a larva inside the mother, which deposits the mature larva in an appropriate microhabitat (Fig. 5).

Flies of the genus Glossina are vectors of the parasite Trypanosoma, that causes African Trypanosomiasis in animals (Nagana in cattle) and humans (Sleeping sickness). Both males and females flies feed on blood and cause painful welts on their hosts. Flies of genus Glossina are found in Africa south of the Tropic of Cancer. The most common species of Trypanosoma transmitted by Glossina spp. are: T. vivax, T. uniforme, T. congolense, $T$. simiae, T. brucei, T. gambiense, T. rhodesiense (Jordan 1976). 


\section{Stomoxys calcitrans (Stable fly) (Dipetra: Muscidae)}

The stable fly, Stomoxys calcitrans, is an hematophagous ectoparasite of a wide variety of domestic and wild animals that has a worldwide distribution (Zumpt 1973) (Figs. 6 and 7). Being the only species of Stomoxys in America, it is found from southern Canada, through the USA and México, and the rest of the countries in the American continent. Worldwide there are 18 species of Stomoxys, including S. calcitrans.

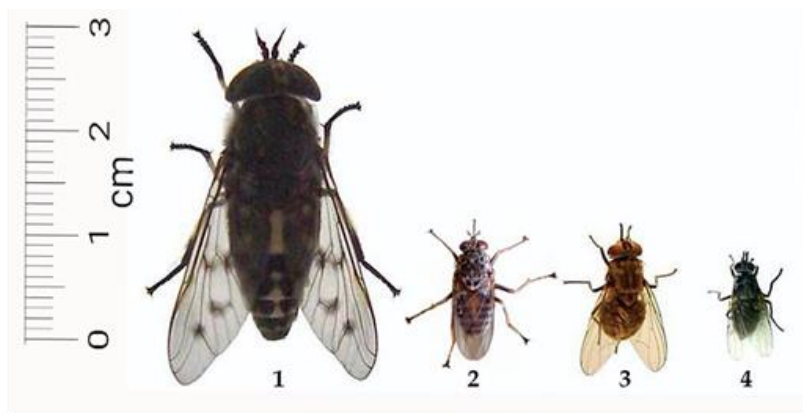

Fig. 1: Comparative size of some haematophagous flies. 1) Tabanus spp., 2) Glossina spp., 3) Stomoxys calcitrans, 4) Haematobia irritans (Figure made by Carlos Ramón BautistaGarfias).

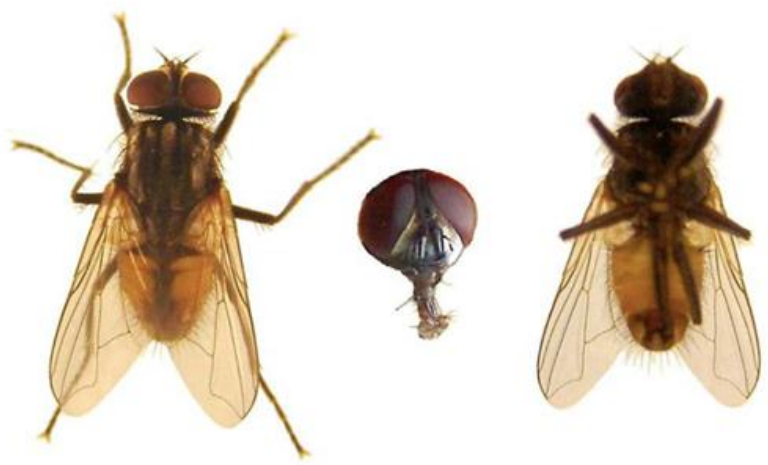

Fig. 2: Musca domestica. Details of the head are shown in the center (Figure made by Carlos Ramón Bautista-Garfias).

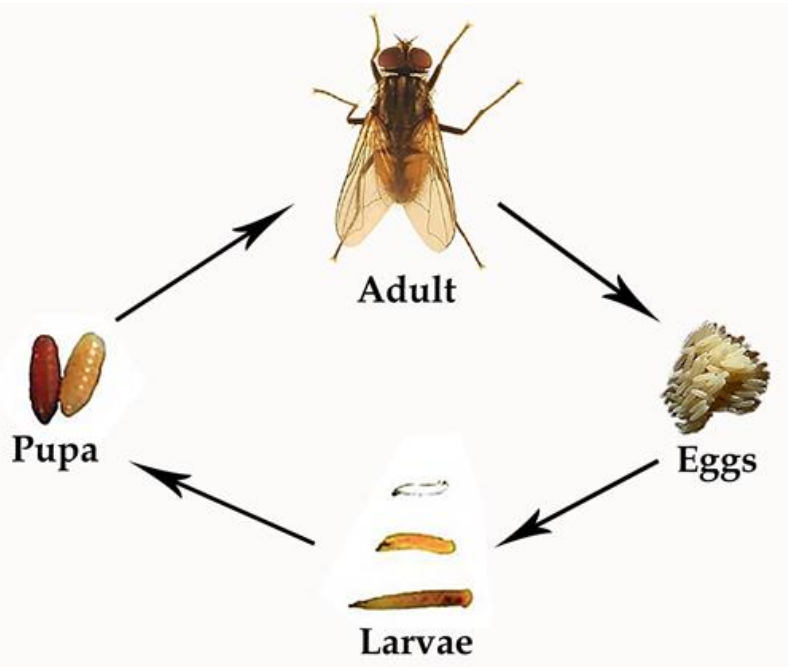

Fig. 3: Life cycle of Musca domestica (Figure made by Carlos Ramón Bautista-Garfias). Is is a holometabolous insect, which comprises egg, larva, pupa and adult stages. The life cycle is completed in seven to 10 days. Adults live for 15 to 28 days.
This genus is believed to have originated in Africa, where the largest number of species is currently found (Scholl et al. 2003). The stable fly, S. calcitrans mechanically transports Anaplasma marginale to cattle, which causes Anaplasmosis, an economically important livestock disease (Bautista-Garfias et al. 2018).

\section{Haematobia irritans (Horn fly) (Diptera: Muscidae)}

The haematophagous horn fly Haematobia irritans (Figs. 8 and 9) has also been implicated in the mechanical transmission of the rickettsia Anaplasma marginale to cattle in Mexico (Rodríguez et al. 2009) and in some areas of the world where there are no ticks (biological vectors) (Bautista-Garfias et al. 2018).

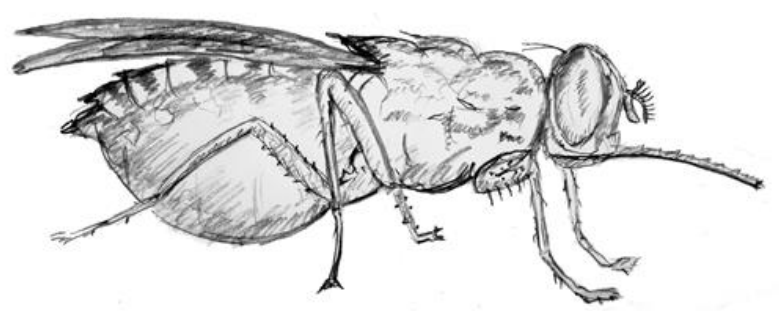

Fig. 4: Glossina spp. after a blood meal (Drawing by Carlos Ramón Bautista-Garfias).

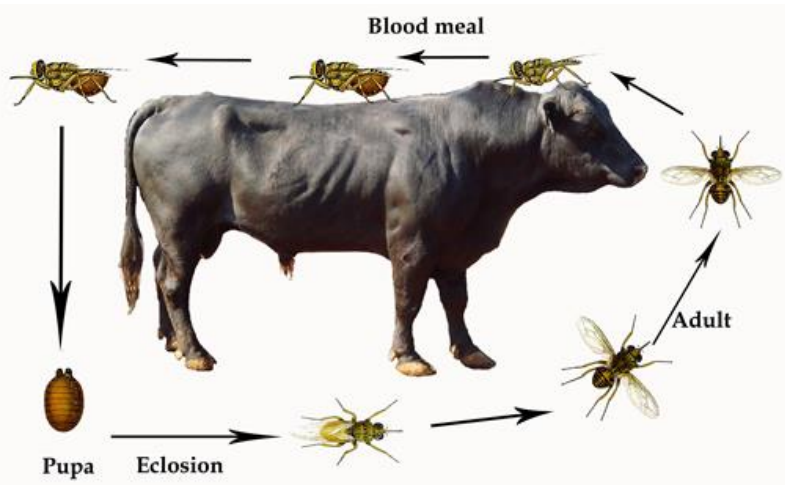

Fig. 5: Life cycle of Glossina spp. (Figure made by Carlos Ramón Bautista-Garfias). This fly is holometabolous, which comprises egg, larva, pupa and adult stages. The life cycle is completed in 38 days. Adult males may live for 15 to 21 days, while females can live for 30 to 120 days.

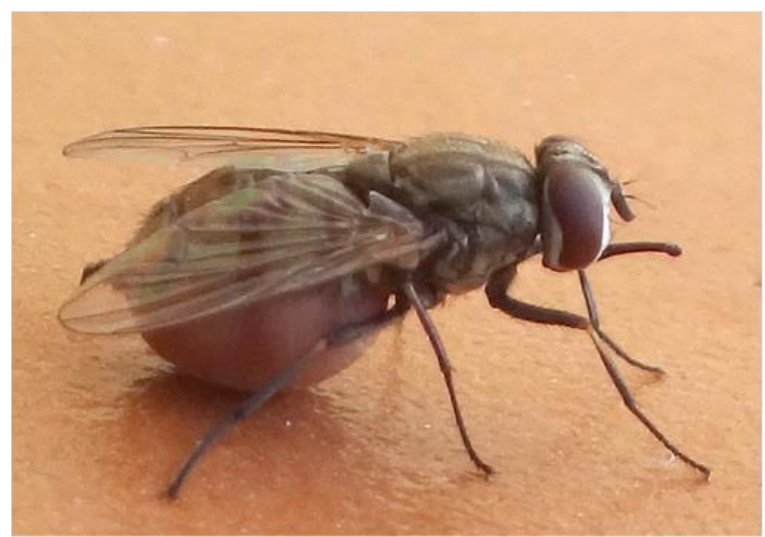

Fig. 6: Stomoxys calcitrans after a blood meal (Photograph by Carlos Ramón Bautista-Garfias). 


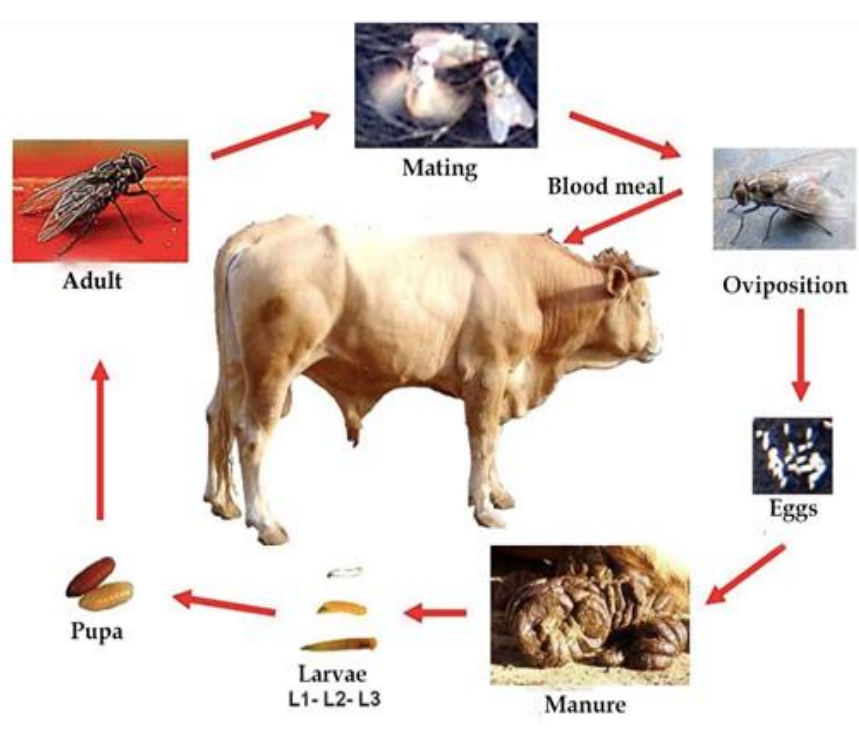

Fig. 7: Life cycle of Stomoxys calcitrans (Figure made by Carlos Ramón Bautista-Garfias). Is is a holometabolous fly which comprises egg, larva, pupa and adult stages. The life cycle is complete in 30 days. Adults live for 24 days (Bautista Garfias 2016).

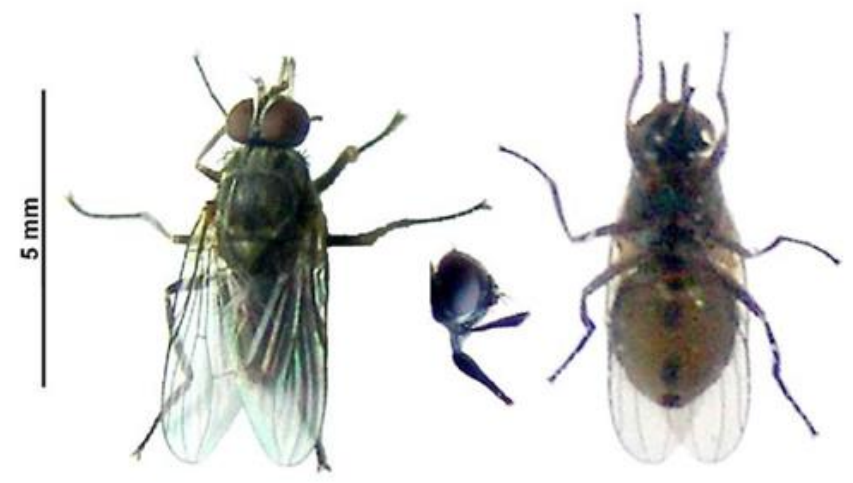

Fig. 8: Haematobia irritans. Details of the head are shown in the center (Photograph by Carlos Ramón Bautista-Garfias).

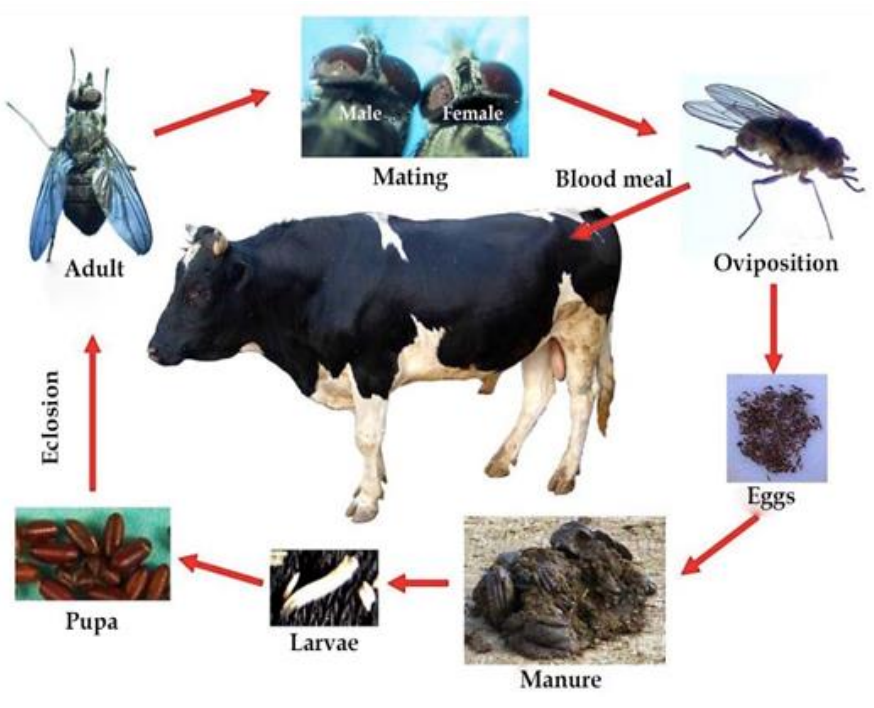

Fig. 9: Life cycle of Haematobia irritans (Figure made by Carlos Ramón Bautista-Garfias). Is is a holometabolous fly which comprises egg, larva, pupa and adult stages. The life cycle is complete in 10 to 20 days. Adults live for 6 to 7 days.

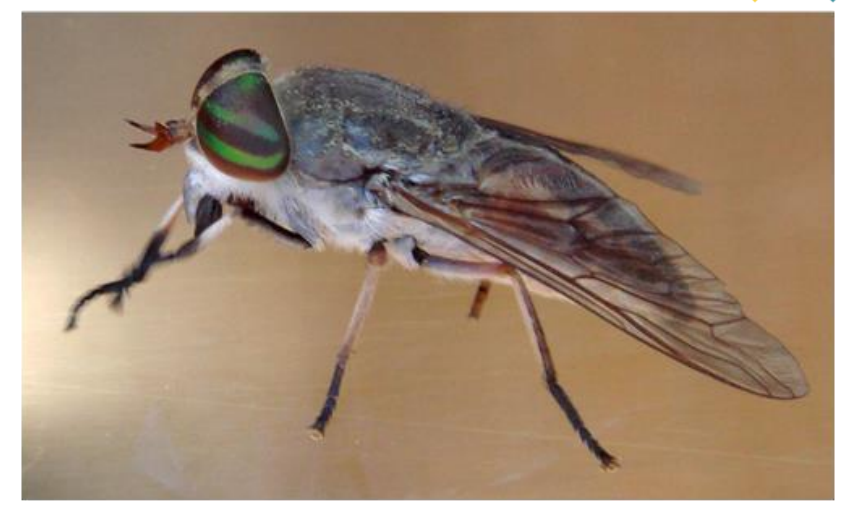

Fig. 10: Tabanus spp. (Photograph by Carlos Ramón BautistaGarfias).

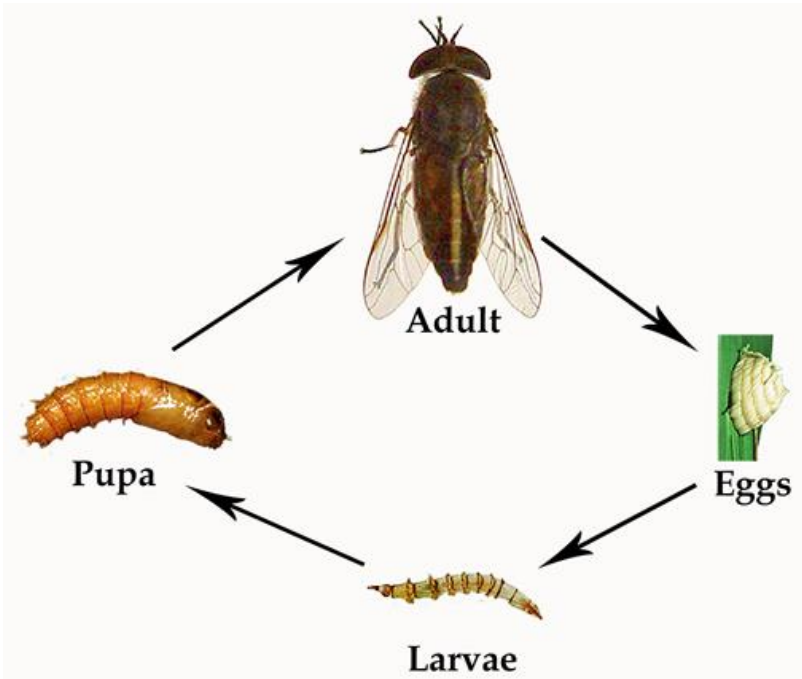

Fig. 11: Life cycle of Tabanus spp. (Figure made by Carlos Ramón Bautista-Garfias). This is a holometabolus insect which comprises egg, larva, pupa and adult stages. The life cycle is completed in 70 days to two years. Adult life span is 30 to 6 o days. Twenty to thirty flies feeding for six hours are capable of taking $100 \mathrm{~mL}$ of blood.

\section{Tabanus spp. (Horse flies) (Diptera: Tabanidae)}

Another important group of hematophagous insects is members of the genus Tabanus, which transmit a wide variety of pathogenic organisms to the domestic animals (Baldacchino et al. 2014). There are approximately 3,000 species of this genus (Bautista Garfias 2016). These insects are very large as compared with other haematophagous flies (Figs. 1, 10 and 11). It has been demonstrated that Tabanus spp. can transmit Trypanosoma evansi (Silva et al. 1995) and Anaplasma marginale in cattle in some areas of the United States of America (Hawkins et al. 1982).

\section{Anaplasmosis}

Bovine Anaplasmosis is a major infectious disease of cattle, first described in 1910 by Sir Arnold Theiler as a different disease than the one produced by Babesia spp. parasites (Theiler 1910a, b, 1911). This is characterized by a mild to severe anemia, jaundice and weight loss in the infected animals that could end in the death of bovines. 
In susceptible cattle, the disease may be present inadvertendly until is too late to treat (Rodríguez et al. 2009).

General overview of the importance in livestock productivity

The World Organization for Animal Health (Office International des Epizooties; OIE) has included Anaplasmosis in the list of bovine infectious diseases that are mandatory declared. To import cattle from an enzootic region, a certificate of health is required (Rodríguez et al. 2009; Almazán et al. 2018). This leads to local and international movement restrictions and translates into socioeconomical issues.

The disease causes losses reaching thousands of US dollars every year in non-enzootic areas, which frequently include death of animals over 2 years old (Ristic 1981; Kocan et al. 2010). The cost of this disease to the livestock production is beyond the cost of treatment; in USA the estimated average cost is \$40o dollars per affected animal (Whitlock 2014; Zabel and Agusto 2018). Infected animals become carriers when they recover, and this represents a risk of cyclic reactivation of the disease, which signifies frequent expenses in treatment and loses of milk or beef production, besides the restriction that is imposed for introduction of genetically improved cattle to lowproduction crossbred cattle herds located in enzootic areas (Rodríguez et al. 2009).

In addition, the reproductive ability of recovered animals might be affected for long periods, situation that can affect enormously when the affected animal is of great genetic merit (Garry 2008). Mathematical modeling of the disease has shown that a producer can expect a $3.6 \%$ reduction in successful calving, 30\% increase in the cull rate and $30 \%$ mortality in adults with clinical disease, when an outbreak occurs in an Anaplasma-free herd (Zabel and Agusto 2018).

\section{Etiological agent}

Bovine Anaplasmosis is caused by Anaplasma marginale (Rickettsiales: Anaplasmataceae). This is an intraerythrocytic pathogen of $0.3-1 \mu \mathrm{m}$ in diameter that can be observed under an optical microscope on blood smears stained with Giemsa or Wright methods (Ristic 1981). The intracellular organism can be observed in the border of red blood cells. The organism is host specific, causing disease in cattle, although it can infect other ruminants that serve as reservoirs (Kocan et al. 2010). The subspecies $A$. centrale may cause minor clinical signs and it is used for the preparation of live vaccine in Israel, Australia, Africa and some South American countries (Theiler 1911; Abdala et al. 1990; Bock and DeVos 2001).

A reclassification placed these organisms in the order of Rickettsiales (Dumler et al. 2001). Thus, two families were defined Rickettsiae and Anaplasmataceae. The first family comprehends obligated intracellular organisms that develop freely in the cytoplasm of eukaryotic cells, while the second family includes organisms that belong to four distinct groups: Anaplasma, Ehrlichia, Wolbachia and Neorickettsia. These organisms are also obligate intracellular parasites that infect eukaryotic cells within membrane-bound vacuoles formed in the cytoplasm of the host cells. These host cells may include erythrocytes, reticuloendothelial cells, bone marrow-derived phagocytic cells, endothelial cells and cells of insect, helminths and arthropods' reproductive tissues.

The genus Anaplasma includes the most pathogenic organisms like $A$. marginale, $A$. marginale subspecie centrale (mainly known just as $A$. centrale), $A$. ovis (that infects sheep), A. bovis (formerly Ehrlichia bovis), A. platys (formerly Ehrlichia platys) and A. phagocytophilum (which itself includes organisms previously known as Ehrlichia equi, E. phagocytophila and the previously unnamed causative agent of human granulocytic ehrlichiosis).

Under natural conditions, $A$. marginale infects the bovine erythrocytes and replicates within them, generating up to eight initial bodies that form a corpuscle or inclusion body. Each of the initial bodies exits the cell to infect another, causing more than $70 \%$ of red blood cells infected during an acute case. The prepatent period ranges from 7 to 6o days, with an average of 28 days, and the percentage of erythrocytes infected depends on the virulence of the strain (García-Ortíz et al. 2000) and the infective dose (Gale et al. 1996; Scoles et al. 2005). In the spleen, the infected cells are phagocytized by reticuloendothelial cells, resulting in anemia and icterus without hemoglobinemia or hemoglobinuria (Rodríguez et al. 2009; Kocan et al. 2010).

\section{Diagnosis}

The most significant signs in acute cases are the loss of appetite, apathy and fever (higher than $41^{\circ} \mathrm{C}$ ). In severe cases, animals present breathing difficulties that can lead to death if there is no timely treatment with the correct drugs. The microscopically detection of inclusion bodies in blood smears (Fig. 12) is used to confirm the diagnosis without molecular or serological tests. However, microscopic evaluation could be difficult if the operators have lack of experience with Anaplasma detection in the edge of erythrocytes (Theiler 1910a; Ristic 1981; Rodríguez et al. 2009; Kocan et al. 2010).

Another clinical sign is the abortion in pregnant females during the last trimester of gestation (Quiroz-Castañeda et al. 2016; Zabel and Agusto 2018). Furthermore, there are some reports describing reductions in serum testosterone levels related to single or co-infections with A. marginale, Babesia spp. and Trypanosoma vivax (Camejo et al. 2016), adversely affecting fertility and reproductive performance.

Persistently infected cattle have life-long immunity and, generally, do not develop clinical disease, unless they are affected by concomitant or stress-related diseases (Rodríguez et al. 2008; Rodríguez et al. 2009). Moreover, the immune and nutritional status of bovines is of great importance in the host response to the infection (RibeiroGasparini et al. 2013). 
Recovered animals may remain as carriers for life. In such chronic cases, there could be production losses, whether in milk or muscular mass (Fig. 13), together with clinical signs of jaundice (Fig. 12). Cyclical peaks of rickettsemia are characterized by fever, low red blood cells count and the presence of $A$. marginale inclusion bodies in the edge of erythrocytes. The count of infected cells may increase in an arithmetical manner during 5 to 10 days. Complications

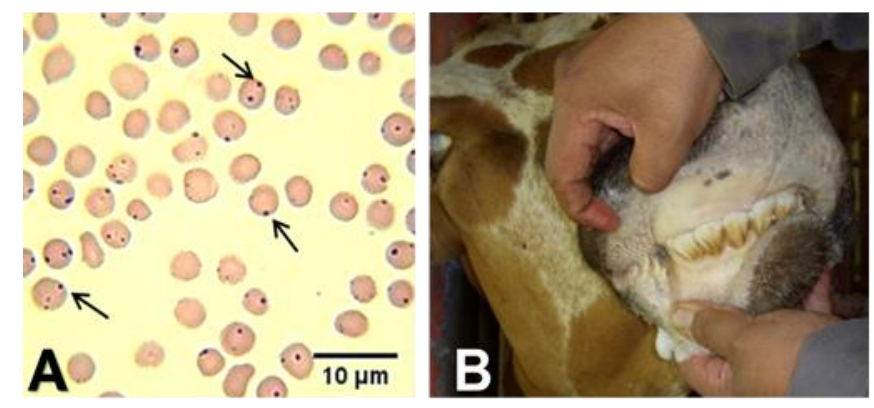

Fig. 12: Anaplasma marginale effects on cattle. A) Giemsa stained blood smear; infected erythrocytes with inclusion bodies of $A$. marginale (arrows). B) Jaundice observed in mouth mucosal tissue of a bovine (Designed by Salinas EE. Photograph by Anaplasmosis Research Unit CENID-SAI INIFAP).

and death may occur if other concomitant diseases are present in the herd, and mostly occurs when farmers introduce new cattle from non-enzootic areas to an enzootic area (Rodríguez et al. 20o9; Quiroz-Castañeda et al. 2016).

Complementary test for diagnosis is an indirect or competitive enzyme immunoassay (ELISA) for detection of antibodies against $A$. marginale. The PCR or qPCR can also be used for the molecular detection of the pathogen DNA in blood samples (Torioni de Echaide et al. 1998; Carelli et al. 2007; Rodríguez et al. 2009; Bacanelli et al. 2014).

\section{Epidemiology}

The disease is enzootic in some areas of North, Central and South America, including the Caribbean Islands. Mediterranean countries have made some reports of this disease, as along-with some countries of Asia and Africa (Kocan et al. 2010). Some of the countries where Anaplasmosis detection has been made either from cattle's blood, ticks or flies and other mechanical flying vectors are shown in Fig. 13 (de la Fuente et al. 2005; Carelli et al. 2007; Rodríguez et al. 2009; Awad et al. 2011; Ait Hamou et al. 2012; Belkahia et al. 2015; El-Ashker et al. 2015; M'ghirbi et al. 2016; Quiroz-Castañeda et al. 2016; Yunik et al. 2016; Aktas et al. 2017; Gondard et al. 2017; Tana-Hernández et al. 2017; Rjeibi et al. 2017; Abdela et al. 2018; Cui et al. 2018; Aydin et al. 2019; Noaman et al. 2019; Kumar et al. 2019; Sprong et al. 2019; Zhou et al. 2019; Zhyldyz et al. 2019; Ringo et al. 2020).

Reports of outbreaks of Anaplasmosis are common in countries geographically located between the Tropic of Cancer and Tropic of Capricorn but not in some mountain regions and desert areas (Kocan et al. 2010). Although climate change, management mistakes and adaptations of the biological vector have made clear that the pathogen can cause outbreaks outside of this geographical range. An outbreak in southern Canada in 2008 showed the importance of disease monitoring and focused on the role of ticks and horse flies in the possible transmission of bovine Anaplasmosis (Yunik et al. 2016). More recently, Bursakov and Kuvalchuk (2019) reported the overall rate of hemoparasite infection in cattle in the Moscow region; and discovered that a remarkably high numbers of the animals were co-infected with $A$. marginale and Theileria spp.

Bovine Anaplasmosis prevalence has been reported in many countries, and varies from one study to another due to several factors, such as the sampling size, detection technique, the moment (in terms of infection) when the sample was taken, the immune state of the animals sampled and other factors such as age, breed, genre, and even the conservation of the samples. A short sample of studies made around the world is shown in Table 1 , where the variation in prevalence among studies is evident.

There are well-defined enzootic regions, primarily due to life-long persistent infections in the recovered bovines. These animals remain as asymptomatic carriers, contributing to spread the disease to susceptible bovines. Besides, there are some regions where sharing grazing grounds with wild-life ruminants contributes to a wider distribution and a larger number of reservoirs for the pathogen (Rodríguez et al. 2009; Kocan et al. 2010).

As shown before, this disease has a worldwide distribution in tropical and subtropical regions related to the presence of its biological vectors. The distribution of Anaplasmosis has shown, and will continue to, change due to international trade movements of cattle and also as a result of global warming, which may influence the movement of the tick hosts (Kocan et al. 2010). In higher altitudes with temperate climate and no ticks present, the main sources of transmission of bovine Anaplasmosis are iatrogenic and mechanical vectors. The latter refers to contaminated objects inadequately used in several animals (like needles) (Reinbold et al. 2010) and, most important and difficult to control, different biting flies.

\section{Transmission}

The transmission of this disease from cow to calf can be common in herds located in enzootic areas. If the cow and the calf are raised in an enzootic area, the calf is born healthy with a low level of infection and this produces protective immunity (Zwart 1985; Gale et al. 1996; Vega et al. 2007; Garry 2008; Ribeiro-Gasparini et al. 2013). When pregnant cows are introduced from a non-enzootic area into an enzootic area, abortion may occur in the third trimester of pregnancy. It may affect the milk production and therefore, the productive value of the recently arrived cow. When the gestation ends normally, the calf may be born with the disease and may die after a few days, if it is not properly treated. 


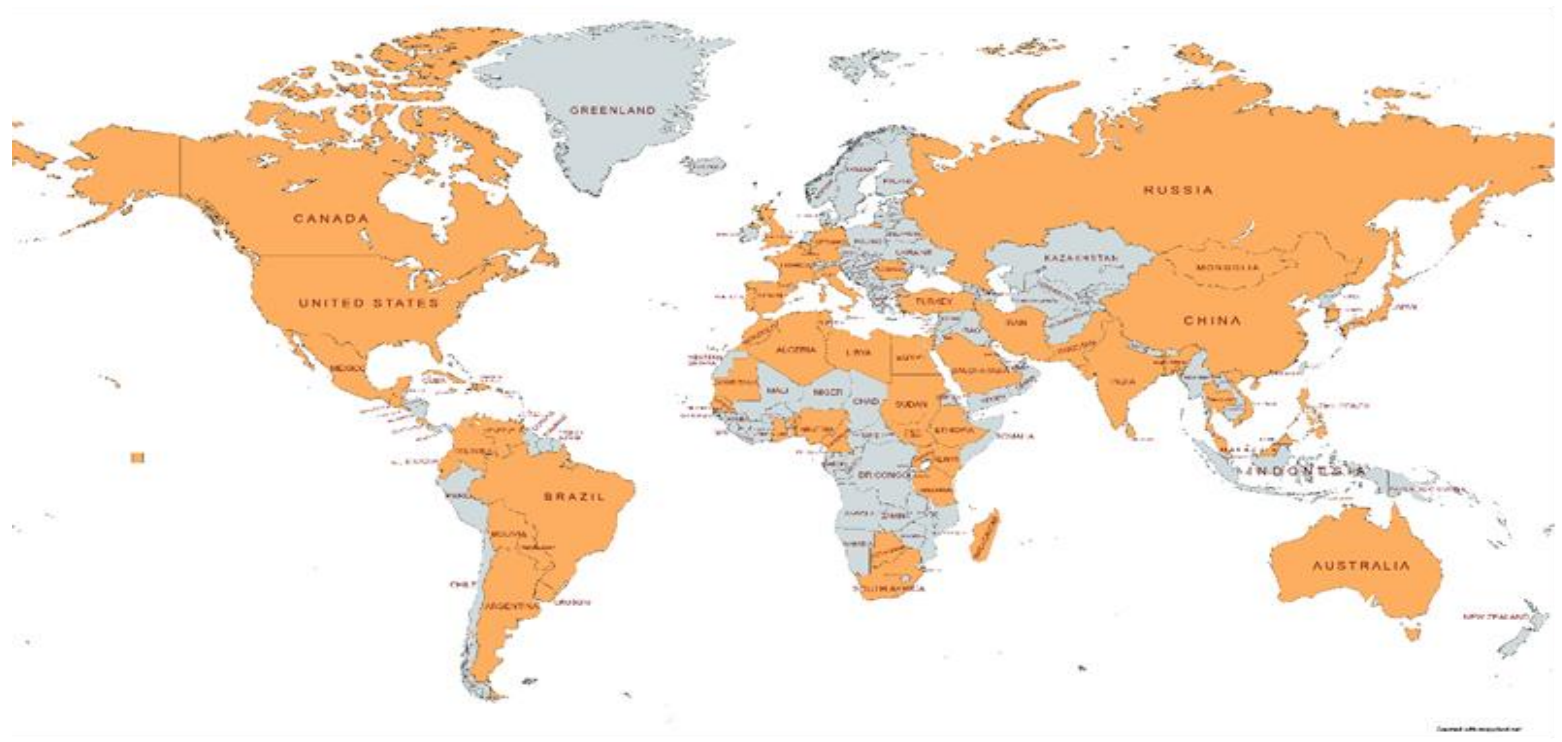

Fig. 13: Detection of bovine Anaplasmosis. Some countries where Anaplasma marginale has been detected are shown in orange. Several of the studies have taken place in small regions or with samples from small herds. There are few countries where an extensive epidemiological study has been made (Designed by Salinas EE, made by MapChart ${ }^{\circledR}$ ).

Table 1: Prevalence of bovine Anaplasmosis in some countries.

\begin{tabular}{|c|c|c|c|c|}
\hline Country & Type of analysis & Prevalence & Number of animals tested & References \\
\hline \multirow[t]{2}{*}{ India } & PCR $(m s p 5)$ & $18.48 \%$ & 211 & Kumar et al. 2019 \\
\hline & Giemsa stained blood smear & $6.64 \%$ & & \\
\hline Iran & PCR $(m s p 4)$ & $44.00 \%$ & 200 & Noaman et al. 2019 \\
\hline Sri Lanka & PCR $(m s p 5)$ & $32.70 \%$ & 437 & Zhyldyz et al. 2019 \\
\hline Rusia & RT-PCR (msp4) & $58.00 \%$ & 113 & Bursakov and Kovalchuk 2019 \\
\hline \multirow[t]{4}{*}{ Turkey } & PCR $(m s p 1)$ & $6.00 \%$ & 150 & Aydin et al. 2019 \\
\hline & Giemsa stained blood smear & $2.67 \%$ & & \\
\hline & $\mathrm{nPCR}(m s p 4)$ & $31.00 \%$ & 247 & Aktas et al. 2017 \\
\hline & Giemsa stained blood smear & $3.80 \%$ & & \\
\hline \multirow[t]{3}{*}{ China } & PCR $(m s p 5)$ & $2.61 \%$ & 345 & Zhou et al. 2019 \\
\hline & PCR $(m s p 4)$ & $25 \cdot 71 \%$ & 35 & Cui et al. 2018 \\
\hline & Giemsa stained blood smear & $80.00 \%$ & & \\
\hline South Korea & cELISA & $7.00 \%$ & 568 & Seo et al. 2018 \\
\hline Ethiopia & Giemsa stained blood smear & $5.10 \%$ & 408 & Abdela et al. 2018 \\
\hline Algeria & PCR (msp4) & $11.10 \%$ & 180 & Rjeibi et al. 2017 \\
\hline Ecuador & PCR (msp5) & $86.10 \%$ & 151 & Tana-Hernández et al. 2017 \\
\hline \multirow[t]{3}{*}{ Tunisia } & PCR (msp4) & $24.70 \%$ & 328 & M'ghirbi et al. 2016 \\
\hline & RT-PCR (mspıb) & $25.40 \%$ & 232 & Belkahia et al. 2015 \\
\hline & PCR $(m s p 4)$ & $4.70 \%$ & 1035 & Belkahia et al. 2015 \\
\hline Egypt & PCR (mspib) & $20.10 \%$ & 164 & El-Ashker et al. 2015 \\
\hline México & cELISA & $67.47 \%$ & 166 & Castañeda-Ortiz et al. 2015 \\
\hline Pakistan & cELISA & $31.05 \%$ & 1050 & Atif et al. 2013 \\
\hline Morocco & nPCR (msp5) & $21.90 \%$ & 668 & Ait Hamou et al. 2012 \\
\hline Sudan & PCR $(m s p 4)$ & $6.10 \%$ & 692 & Awad et al. 2011 \\
\hline Bolivia & Giemsa stained blood smear & $6.90 \%$ & 160 & Mercado et al. 2011 \\
\hline Brasil & cELISA & $58.74 \%$ & 223 & Marangoni-Marana et al. 2009 \\
\hline
\end{tabular}

Ticks are the biological vector. The transmission mechanism most commonly known was studied with Rhipicephalus microplus, which is also the most widely distributed cattle tick, and, like some species of Dermacentor, were reported to be a vector of the pathogen causing Anaplasmosis (Futse et al. 2003; Kocan et al. 2004; Scoles et al. 2005; Rodríguez-Vivas et al. 2006). The transmission by ticks is efficient, since the amount of rickettsia transmitted by ticks does not depend on the level of rickettsemia in the bovine at the moment of feeding.
The A. marginale replicates in the midgut epithelium and in the salivary glands of the tick (Lohr et al. 2002, Futse et al. 2003; Scoles et al. 2005). However, some strains of $A$. marginale are not transmitted by ticks but by flies or mosquitoes (Kocan et al. 2004; Scoles et al. 2005). The replication within the tick tissues and the intrastadial, transtadial and transovaric transmission makes arthropods the primary reservoir for the pathogen (Amaro et al. 2020).

The iatrogenic ways of transmission are not so common. These may include the repeated use of a single needle 
among several bovines or the use of other fomites, including castration instruments, dehorning saws, tattooing instruments and ear tagging devices (Reinbold et al. 2010; Kocan et al. 2010).

Mechanical transmission by biting flies (similar to the use of contaminated instruments on several animals) explains the spread of the disease in the absence of ticks. There have been several reports, involving a large number of flies in transmission of Anaplasmosis, but just a few of them have been studied under natural conditions. In livestock, their direct effects are disturbance, skin lesions, reduction of feed intake, stress, blood loss, and a global immunosuppressive effect (Baldacchino et al. 2013). The common stable fly (Stomoxys calcitrans) is one of the species that can transmit the pathogen in the mechanical form. Scoles et al. (2005) determined by qPCR that the acquisition of $A$. marginale was low, even 20 minutes after feeding, and this value increased when the infection increased on the host.

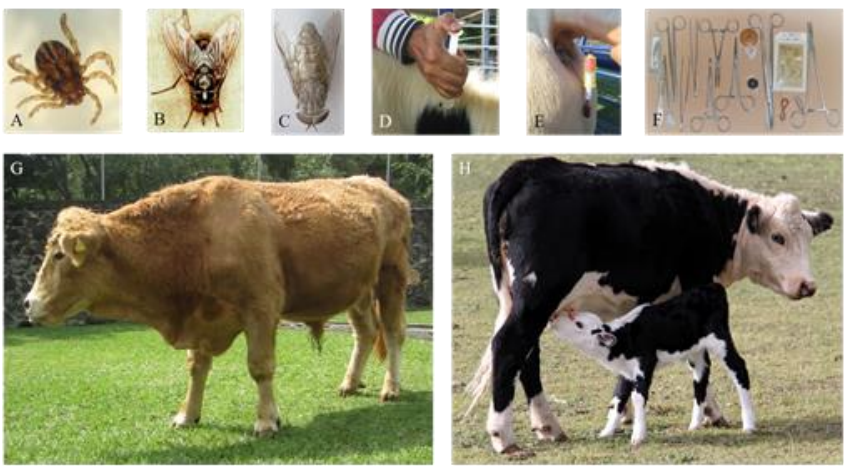

Fig. 14: Transmission of bovine Anaplasmosis. A) Ticks, also the biological vector, B) Flies and C) Tabanids, both act as mechanical vectors. Iatrogenic ways of transmission that require the incorrect use of the same needle in two or more animals are D) application of antibiotics, vaccines or other drugs and E) sampling; F) the incorrect use or lack of sterilization of surgical equipment contaminated with infected blood. G) Susceptible bovine that may be infected by either of the ways mentioned before. Last way of transmission is $\mathrm{H}$ ) from the cow to the calf (Designed by Salinas EE. Photograph by Anaplasmosis Research Unit CENID-SAI INIFAP).

The transmission of disease by stable flies fails, either because of desiccation or due to some inhibitor components on the saliva of the flies. Another explanation is that at least a portion of the infected erythrocytes remains on the mouthparts after the transmission feeding, also, 20 minutes after feeding the proportion of flies with measurable amounts of $A$. marginale on their mouthparts was reduced. Mechanical transmission by direct transfer of flies from an infected to a susceptible host is at least two orders of magnitude less efficient than tick-borne biological transmission.

This indicates that the transmission occurs within minutes due to the short period that $A$. marginale can survive in mechanical vectors and the quantity of biting flies present at the same time on an animal most be large enough to generate a high rickettsemia (Zwart 1985).
The second fly species is the horn fly (Haematobia irritans) which, besides the traumatic effect on the hide quality, causes stress by the infestation interfering with cattle feeding and this generates a reduction in meat and milk production. Flies leave the host only to move to other hosts or to lay eggs on fresh manure (Torres et al. 2012). In order to confirm the participation of this fly, some analysis has been made. In a study made in a tropical region in Mexico, male calves appeared to attract more flies than female calves, and lighter coat color of breed-crosses attracted fewer flies than black and redblack coat colors of other breeds and crosses.

Finally, temperature and rainfall were the environmental factors that influenced higher fly infestations (RodríguezGallegos and Acosta-Rodríguez 2011). In Australia, a similarity in the distribution of the cattle tick and the buffalo fly (Haematobia irritans exigua) raised the question whether the presence of $A$. marginale could be more associated with the presence of flies than thought before. The experiments were made on spleenectomized calves giving an unrealistic scenery about the feeding and transmission potential, nonetheless the results of transmission were negative, indicating that not all species of Tabanids have a role in the epidemiology of Anaplasmosis (Allingham et al. 1994). Another study corroborated that Haematobia spp. was not important as a mechanical vector of Anaplasma spp. (Hornok et al. 20o8). However, their contribution to a lack of welfare is notorious and it has to be analyzed in order to control the population of these flies.

The third genre most studied is the horse fly (Tabanus bovinus and $T$. fuscicostatus) which, besides the risk of transmission of pathogens and the blood feeding, produces a higher level of discomfort for the animals. Tabanid horse flies species may be more important for their mechanical role in transmission of $A$. marginale than the biological vector in the spreading of this pathogen in places were ticks are not abundant. Tabanid females suck blood only every 3-4 days, but their painful feeding is usually interrupted by host animals several times, allowing mechanical transfer of pathogens.

Although remaining able to inoculate $A$. marginale for at least $2 \mathrm{~h}$ during which $T$. bovinus can cover several $\mathrm{km}$ with its flight speed around $5 \mathrm{~m} / \mathrm{s}$, they tend to feed in the same herd until completing their blood meal (Foil 1989; Hornok et al. 2008). Scoles et al. (2008) showed that Tabanid-borne mechanical transmission is at the minimum two orders of magnitude less efficient than tick-borne biological transmission. Still, there are many places around the world where Tabanids species may be the principal carriers of $A$. marginale.

It has been reported that transmission by biting flies is less efficient than transmission by ticks, due its dependence on the rickettsemia level of the host (Scoles et al. 2005). However, transmission by flies is of great concern in those places where the population of flies is abundant and difficult to control and ticks are absent or they are not the principal vector. The latter is the case for certain areas of Africa, USA, Central and South America (Foil 1989; Figueroa et al. 1998; Coronado 2001; Baldacchino et al. 2013). 


\section{Control}

The development of a worldwide protective vaccine and an effective antimicrobial for clearance of carrier bovines are two of the main goals for the Anaplasmosis research. However, current strategies and measures for control of Anaplasmosis are not very different from the ones employed in the past. In general, these strategies are based on the control of biological vector, prophylactic antibiotic administration, control of fomites and restrictions in animal trade between non-enzootic and enzootic areas. Simple management practices can decrease the incidence of Anaplasmosis within the herd, such as decreasing the number of movements for sanitary activities. This can be achieved by an adequate vaccination/deworming calendar with the objective of making the less possible movements to the herd (Almazán et al. 2018; Zabel and Agusto 2018). Education and training of personnel is important to achieve control of infectious diseases.

Control of horn flies mainly relies on the use of insecticides, but issues with resistance have increased interest in development of alternative means of control (Madhav et al. 2019). In parallel, inadequate use of acaricides for tick control have contributed to an increasing resistance against chemical components. However, there are no current guidelines to introduce any recommendation for farmers after resistance is detected (Estrada-Peña and Salman 2013). This situation generates a frequent administration of products, increasing the cost of control expenses, which also increase the production. Methods based on vector control may also affect the environment due to residues of the chemicals deposited on the soil and water (Rodríguez-Vivas et al. 2006; Almazán et al. 2018).

Another approach that has been developed is keeping cattle in an environment that is not favorable for survival and completion of the life cycle of ticks. However, this may represent additional costs that could be difficult to manage for some farmers. Integrated pest management combines sanitation practices, biological control and chemical agents to reduce tick and fly populations. Biological control of ticks and flies is highly recommended and is based on natural enemies (beetles, mites and parasitic wasps, or parasitoids) (Aubry and Geale 2011). The use of certain types of grass and bushes that tend to repel ticks has also been suggested. All these methods should be combined with rotational grazing (Almazán et al. 2018). The discovery of Bm86, a gut membrane protein found in the intestine of $R$. microplus, in the 8o's resulted in the development of anti-tick vaccines. Cattle vaccinated with $\mathrm{Bm} 86$ experience a reduction in the number of engorging females, their weight, and reproductive capacity, leading to reduced tick numbers after several generations (Almazán et al. 2018). The discovery of vaccines against ticks is one of the most promising branches in the research of tick-borne and flyborne diseases that could contribute to an improvement in environment care and animal welfare.

In the past, the treatment of acute bovine Anaplasmosis was based on a variety of chemotherapeutic agents, including arsenicals, antimalarials, antimony derivatives and dyes. These compounds had little or no chemotherapeutic effects. Due to the close relation of this disease with Babesiosis, imidocarb dipropionate was used in some places to treat animals suspected for $A$. marginale infection, although it has been restricted due to prolonged retention of the drug in edible tissues of food producing animals (Kocan et al. 2010).

The treatment of Anaplasmosis consists of the administration of tetracyclines (Swift and Thomas 1983). Although other antibiotics, including enrofloxacin, have been studied (Coetzee et al. 2005; Coetzee et al. 2006), none has been shown to clear persistent infections in carrier bovines. The dosage recommended by the OIE is based on five daily injections of oxytetracycline administered intravenously at $22 \mathrm{mg} / \mathrm{kg}$ body weight. These antibiotics have been used in a prophylactic approach when introducing naïve animals into an enzootic herd (Rodríguez et al. 2009; Quiroz-Castañeda et al. 2016; Almazán et al. 2018). Despite their efficiency in the control of the disease, repeated administration of tetracyclines constitutes a risk in itself, as it enhances the emergence of antibiotic resistance for many other microorganisms.

Live vaccines have been developed almost since the discovery of $A$. marginale, but this has restrictions in several countries due the inexistence of the vaccine agent A. centrale in their territories (Theiler 1911; Abdala et al. 1990). Inactivated strains and low virulence strains of $A$. marginale have been tested and showed some protection against homologous challenge but showed a low or no protection against heterologous challenge (Rodríguez et al. 2000; Vega et al. 2007; Rodríguez et al. 2008; Almazán et al. 2018). In addition, this method represents a risk of transmission of other microorganisms.

The use of recombinant highly immunogenic proteins has been evaluated with similar results, most probably due to the presence of great diversity among different strains. The genomics approach is now the one on the focus to develop a vaccine that could be safer and effective against all the strains of $A$. marginale. The success of new vaccines, using molecular technologies, for Anaplasmosis will depend on their cross protection between genotypes and to either mimic or redirect the host response during natural infections or block infection of host cells (Kocan et al. 2010; Almazán et al. 2018). An integrated approach is needed to prevent the vector infestation and the infection of the pathogen by the development of safer and effective vaccines. Research in the control of, and vaccination against, Anaplasmosis is still a great goal. When accomplished, it will contribute greatly to bovine health, food security and environment care with direct effect on human health.

\section{African Trypanosomiasis}

\section{Generalities}

Mainly known as American Trypanosomiasis and African Trypanosomiasis (Cevallos and Hernandez 2020), these 
diseases belong to the family Trypanosomatidae and are characterized by an organelle called kinetoplastid. The genus Trypanosoma is characterized by the use of two hosts, one vertebrate and one invertebrate, to carry out its life cycle. The most studied species of this genus are $T$. cruzi and $T$. brucei. These are different subgenera and therefore, their biological aspects are different. The diseases for each of these infections are Chagas disease and sleeping sickness (America and Africa).

Chagas disease is a zoonosis caused by $T$. cruzi, which was described in 1909 by the Brazilian doctor Carlos Chagas and the doctor Salvador Mazza, naming it "Chagas-Mazza disease". This disease is localized only in America, mainly in the jungle, where triatomines, as well as various mammals including opossums, raccoons and rats, act as vectors.

This interaction has been mainly due to the invasion of rainforests by humans. These people can be bitten by infected bedbugs and start the transmission of the disease. Triatomines are "hemimetabolous", they do not have a pupal stage and have an incomplete metamorphosis. The stages they go through include eggs, nymphs and adults; this stage development can last from six months to one year (Fig. 15).

Human African Trypanosomiasis is a disease caused by protozoan Trypanosoma brucei (gambiense and rhodesiense). In the case of the parasite T.b gambiense, it is considered a more chronic disease that is localized in West and Central Africa. This disease is transmitted by the bite of a fly, known as tsetse fly (Glossina palpalis, G. tachinoides, G. morsitans, G. pallidipes, G. swynnertoni and G. fuscipes) (Roche 2004). The classification of African Trypanosomes according to Cordon-Obras et al. (2013) is set out in Table 2.

In general, African Trypanosomes are reported to parasitise a large number of domestic and wild vertebrates (cattle, swine, equidae, giraffes), primates and carnivores (canids, felids, mustelids) (Isobe et al. 2003). Only two African Trypanosomes have been reported to be able to survive in human serum, these are T.b gambiense and T.b rhodesiense. They can cause disease in humans, which can lead to anemia, fever, edema and sometimes death. The tsetse fly is the only vector for T.b gambiense and T.b rhodesiense. A map, showing distribution of the African disease in humans is presented in Fig. 16 (Simarro et al. 2013).

T.b gambiense and T.b rhodesiense are distinguished by their geographical distribution. T. rhodesiense is found in East Africa and T. gambiense in West and Central Africa. (Rhodesia is the former name of Zimbabwe). Other differences that can be found between T.b gambiense and T. $b$ rhodesiense, can be found in Table 3 described by Mark (1999).

Molecular data suggest that $T$. rhodesiense may be a variant of $T$. brucei in the host range. Molecular techniques also show that $T$. gambiense is relatively homogeneous across its wide distribution in central and West Africa.

Furthermore, a mutation in an ancestral T. brucei conferred human infectivity and thus represented the origin of T. rhodesiense. Therefore, T. rhodesiense can be considered as a variant of the host range of $T$. brucei (Gibson 2002).

\section{Biology}

The genus Trypanosoma has an elongated morphology, cell size varies from $18-42 \mu \mathrm{m}$ in length and $1-3 \mu \mathrm{m}$ in width. It also has the basic organelles of eukaryotic cells, the Golgi apparatus, ribosomes, mitochondria, nucleus and endoplasmic reticulum. In addition, the surface of the parasite is coated with proteins for protection from the immune response. In general, there are different morphological forms of Trypanosomes: trypomastigote, epimastigote, promastigote and amastigote. The differentiation of these forms is based on the position of the kinetoplast in relation to the nucleus, and by the presence or absence of the undulating membrane. These morphological forms can be seen in Fig. 17.

For Trypanosoma cruzi disease: The etiological agent is characterized by the presence of a single flagellum and a single mitochondrion. Three groups of T. cruzi strains have been differentiated. They are the TCI lineage, which is a wild strain and has been reported mainly in the highlands of Chile-Bolivia. TC2 is a domestic cycle. On the other hand, the African Trypanosimiasis genera are characterized by some variations in morphology and physiology. The subgenus Trypanozoom is characterized by a kinetoplast, which develops in the salivary glands and midgut of the vector (Fig. 18).

The genome of $T$. brucei is reported to have 11 chromosomes. Furthermore, the genome has already been sequenced and is available in several databases.

\section{Life cycle of Trypanosoma brucei gambiense}

The life cycle of $T$. $b$. gambiense begins when an infected tse tse fly injects metacyclic trypomastigotes into the skin tissue of a mammalian host. The parasites enter the lymphatic system and pass into the blood stream. Once inside the host, the parasites transform into trypomastigotes in the blood stream, travel to other sites throughout the body, and also enter body fluids, such as lymph and cerebrospinal fluid. Later, trypomastigotes

Table 2: The classification of African trypanosomes taken from Cordon-Obras (2013).

\begin{tabular}{lll}
\hline Taxon & Name & Descriptor \\
\hline Genus & Trypanosoma & Gruby 1843 \\
Subgenus & Trypanozoom & Lühe 1906 \\
Specie & Trypanosoma brucei brucei & Plimmer and Bradford \\
& Trypanosoma brucei & 1899 \\
& gambiense & Dutton 1902 \\
& Trypanosoma brucei & Stephens and fantham \\
& rhodesiense & 1910 \\
& Trypanosoma evansi & Balbiani 1888 \\
& Trypanosoma equiperdum & Doflein 1901 \\
Subgenus & Nannomonas & Hoare 1964 \\
Specie & Trypanosoma congolense & Broden 1904 \\
& Trypanosoma simiae & Bruce 1912 \\
Subgenus & Duttonella & Chalmer 1918 \\
Specie & Trypanosoma vivax & Zieman 1905 \\
\hline
\end{tabular}


Table 3: Differences between T.b gambiense and T.b rhodesiense, described by Mark (1999).

\begin{tabular}{|c|c|c|}
\hline Attribute & T. rhodesiense & T. gambiense \\
\hline $\begin{array}{l}\text { tse tse vector } \\
\text { ecology } \\
\text { transmission } \\
\text { cycle }\end{array}$ & $\begin{array}{l}\text { G. morsitans group } \\
\text { dry bush, woodland } \\
\text { ungulate-fly-human }\end{array}$ & $\begin{array}{l}\text { G. palpalis group } \\
\text { rainforest, riverine, lakes } \\
\text { human-fly-human }\end{array}$ \\
\hline $\begin{array}{l}\text { non-human } \\
\text { reservoir }\end{array}$ & wild animals & domestic animals \\
\hline epidemiology & sporadic, safaris & $\begin{array}{l}\text { endemic, some } \\
\text { epidemics }\end{array}$ \\
\hline $\begin{array}{l}\text { disease } \\
\text { progression }\end{array}$ & rapid, often fatal & $\begin{array}{l}\text { slow }(\sim 1 \text { yr }) \text { acute } \Rightarrow \\
\text { chronic }\end{array}$ \\
\hline parasitemia & high & low \\
\hline $\begin{array}{l}\text { asymptomatic } \\
\text { carriers }\end{array}$ & rare & common \\
\hline
\end{tabular}

multiply by binary fission and circulate in the blood stream. By ingesting blood from an infected mammalian host, the tse tse fly becomes infected with trypomastigotes present in the blood stream. In the midgut of the tse tse fly, parasites are transformed into procyclic trypomastigotes and multiply by binary fission. The procyclic trypomastigotes leave the midgut, become epimastigotes and reach the salivary glands of the fly, multiply by binary fission and become metacyclic trypomastigotes (Fernandes-Rodríguez et al. 2014).

\section{Diagnosis}

The diagnosis of African Trypanosomiasis is established by direct techniques in the acute phase that are based on the parasitological examination of blood and cerebrospinal fluid. Indirect diagnostic techniques are used when the disease affects the central nervous system. A more specific and highly sensitive test is the polymerase chain reaction (PCR) that allows the identification of the genus, species, subspecies or type of parasites, depending on the cases. The highly specific primers or the sequencing of the PCR products allow the identification of $T$. brucei spp. zoonotic, which provides de "novo" information on the role of domestic and wild animals in the maintenance of some spotlights of sleeping sickness (Hopkins et al. 1998; Holland et al. 2001). On the other hand, there is also the serological test called indirect immunofluorecence and the detection of antibodies by ELISA, both tests are used routinely for the detection of antibodies against Trypanosoma in cattle (Greiner et al. 1997).

\section{Control}

There are various control methods for African Trypanosomiasis. The first one is to eliminate or eradicate the vectors (tse tse fly), mainly through destroying the places where they reproduce. On the other hand, insecticides, especially "organochlorines" have been widely used for the eradication of tse tse flies. The most widely used insecticides are dicloro difenil tricloroetano (DDT) and dieldrin, the former being the product used to eradicate the Zululand tse tse fly in South Africa; it would

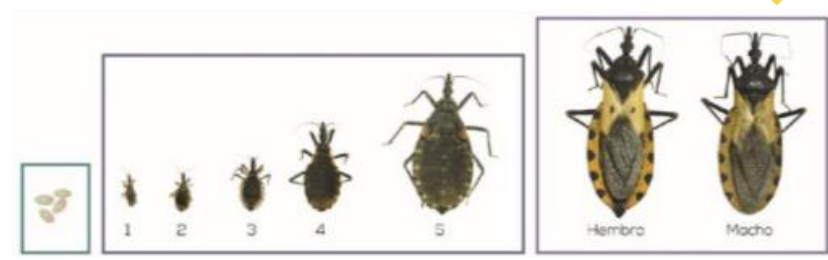

Fig. 15: Life cycle of triatomata. Figure taken from "Manual de vigilancia y control de la enfermedad de chagas en el Ecuador", 2020.

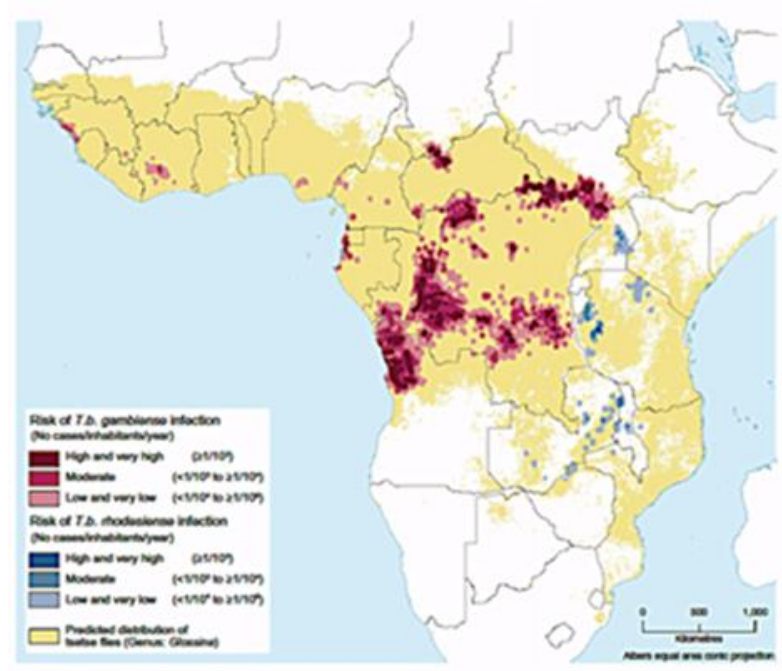

Fig. 16: Human African Trypanosomiasis distribution map from Simarro et al. (2013).
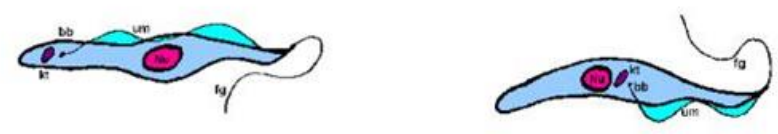

Tripomastigote

Epimastigote
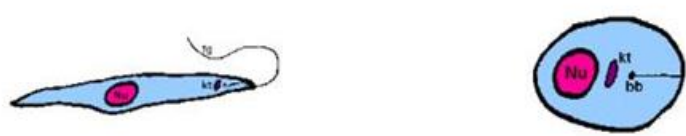

Promastigote

Amastigote

Fig. 17: Morphological stages of trypanosomatids from Cevallos and Hernández (2020).

be feasible only if considerable international cooperation is achieved (Odeniran et al. 2018). Eradication by means of insecticides of chemical origin has an important disadvantage of affecting other arthropods and beneficial organisms. Another method is "chemotherapy"; however, resistance against different drugs has already developed (Schofield and Maudlin 2001).

The economically most important parasitic diseases transmitted to farm animals from flies were reviewed in this chapter. The present review focuses mainly on diseases transmitted biologically or mechanically by the following fly species or genera: Musca domestica, Glossina spp., Stomoxys calcitrans, Haematobia irritans, and 


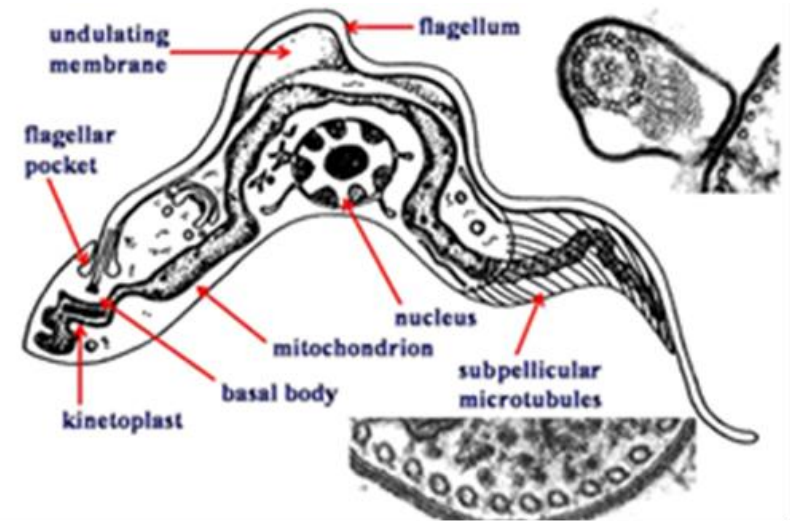

Fig. 18: The subgenus Trypanozoom is characterized by a kinetoplast, which develops in the salivary glands and midgut of the vector (taken from Mark 1999).

Tabanus spp. Similarly, some aspects of fly biology were reviewed alongside the most important parasitic diseases caused by African trypanosomes (Trypanosoma spp.) and the hemotropic rickettsia Anaplasma marginale, which was once considered as a parasite.

\section{REFERENCES}

Abdala AA et al., 1990. Frozen and fresh Anaplasma centrale vaccines in the protection of cattle against Anaplasma marginale infection. Revue d Elevage et de Medecine Veterinaire des Pays Tropicaux 43: 155-158.

Abdela $\mathrm{N}$ et al., 2018. Prevalence, risk factors and vectors identification of bovine Anaplasmosis and Babesiosis in and around Jimma town, Southwestern Ethiopia. Acta Tropica 177: 9-18.

Ait Hamou S et al., 2012. Molecular and serological prevalence of Anaplasma marginale in cattle of North Central Morocco. Research in Veterinary Science 93: 1318-1323.

Aktas M et al., 2017. Outbreak of Anaplasmosis associated with novel genetic variants of Anaplasma marginale in a dairy cattle. Comparative Immunology, Microbiology and Infectious Diseases 54: 20-26.

Allingham PG et al., 1994. An attempt to transmit Anaplasma marginale by buffalo flies (Haematobia irritans exigua). Australian Veterinary Journal 71(4): 122-123.

Almazán C et al., 2018. Immunological control of ticks and tick-borne diseases that impact cattle health and production. Frontiers in Bioscience, Landmark 23: 1535-1551.

Amaro EI et al., 2020. Transmisión transovárica de Anaplasma marginale por larvas no alimentadas de garrapata Rhipicephalus microplus bajo condiciones experimentales, Revista Mexicana de Ciencias Pecuarias 11: 116-131.

Atif FA et al., 2013. Seroprevalence of Anaplasma marginale infection among cattle from three districts of the northern Punjab, Pakistan. The Journal of Animal and Plant Sciences 23: 995-998.

Aubry P and Geale DW, 2011. A review of Bovine Anaplasmosis. Transboundary and Emerging Diseases
58: 1-30.

Awad $\mathrm{H}$ et al., 2011. Prevalence and genetic diversity of Babesia and Anaplasma species in cattle in Sudan. Veterinary Parasitology 181: 146-152.

Aydin MF et al., 2019. Molecular survey of Anaplasma and Ehrlichia species in cattle from Karaman of Turkey, including a novel tandem report of Anaplasma marginale mspıa gene. Ankara Üniversity Veteriner Fakultesi Dergisi 66: 255-26o.

Bacanelli GM et al., 2014. Molecular diagnosis of Anaplasma marginale in cattle: Quantitative evaluation of a real-time PCR (Polymerase Chain Reaction) based on msp5 gene. Pesquisa Veterinária Brasileira 34: 29-33.

Baldacchino F et al., 2014. Tabanids: Neglected subjects of research, but important vectors of disease agents. Infection, Genetics and Evolution 28: 596-615.

Baldacchino F et al., 2013. Transmission of pathogens by Stomoxys flies (Diptera, Muscidae): A review. Parasite Bautista Garfias CR, 2016. Entomología Veterinaria Esencial. 2nd Edition, INIFAP, México City, México.

Bautista-Garfias CR et al., 2018. Detection of Anaplasma marginale in stable flies Stomoxys calcitrans (Diptera: Muscidae) feeding on a tick-free bovine herd, 2018. Veterinaria México OA. 2018: 5. doi: 10.21753/ vmoa.5.1.436

Belkahia $\mathrm{H}$ et al., 2015. First molecular survey and novel genetic variants' identification of Anaplasma marginale: $A$. centrale and $A$. bovis in cattle from Tunisia. Infection, Genetics and Evolution 34:361-371.

Bock RE and de Vos AJ, 2001. Immunity following use of Australian tick fever vaccine: A review of the evidence. Australian Veterinary Journal 79: 832-839.

Bursakov SA and Kovalchuk SN, 2019. Co-infection with tick-borne disease agents in cattle in Russia. Ticks and Tick-Borne Diseases 10: 709-713.

Buzzell GR et al., 2011. Morphology of the infective larval stage of the equid parasite Habronema muscae (Spirurida: Habronematidae) from houseflies (Musca domestica). Parasitology Research 108: 629-632.

Camejo MI et al., 2016. Relationship between asymptomatic infections with Anaplasma marginale, Babesia spp. and Trypanosoma vivax in bulls and testosterone levels. Revista Científica de la Facultad de Ciencias Veterinarias de la Universidad del Zulia 26: 13-19.

Carelli G et al., 2007. Detection and quantification of Anaplasma marginale DNA in blood samples of cattle by real-time PCR. Veterinary Microbiology 124: 107114.

Cevallos A and Hernández R, 2020. Trypanosoma cruzi y la enfermedad de Chagas (tripanosomiasis americana). Departamento Biología Molecular, Instituto de Investigaciones Biomédicas, Universidad Nacional Autónoma de México. http://www.biblioweb.tic.unam.mx/libros/microbios/ Cap15/\#: :text=brucei\%2ocomo\%2oespecies\%2oherm anas $\% 3 \mathrm{~B} \%$ 2osin,replica\%2oen\%2oel\%2otorrente $\% 20$ s angu $\% \mathrm{C}_{3} \%$ ADneo 
Castañeda-Ortiz EJ et al., 2015. Association of Anaplasma marginale strain superinfection with infection prevalence within tropical regions. PLoS One 10: e0129415. https://doi.org/10.1371/journal.pone.0129415.

Coetzee JF et al., 2005. Comparison of three oxytetracycline regimes for the treatment of persistent Anaplasma marginale infections in beef cattle. Veterinary Parasitology 127: 61-73.

Coetzee JF et al., 2006. Comparison of the efficacy of enrofloxacin, imidocarb, and oxytetracycline for clearance of persistent Anaplasma marginale infections in cattle. Veterinary Therapeutics 7: 347360.

Cordon-Obras C, 2013. Epidemiología de la tripanosomiasis humana africana en los focos históricos de guinea ecuatorial y aproximación traslacional a la existencia de reservorios animales. Tesis Doctoral 27.

Coronado A, 2001. Is Boophilus microplus the main vector of Anaplasma marginale? Technical note. Revista Científica de la Facultad de Ciencias Veterinarias de la Universidad del Zulia 11: 408-411.

Cui Y et al., 2018. First confirmed report of outbreak of Theileriosis/Anaplasmosis in a cattle farm in Henan, China. Acta Tropica 177: 207-210.

de la Fuente J et al., 2005. Serologic and molecular characterization of Anaplasma species infection in farm animals and ticks from Sicily. Veterinary Parasitology 133: 357-362.

Dumler JS et al., 2001. Reorganization of the genera in the families Rickettsiaceae and Anaplasmataceae in the order Rickettsiales: Unification of some species of Ehrlichia with Anaplasma, Cowdria with Ehrlichia and Ehrlichia with Neorickettsia, descriptions of six new species combinations and designation of Ehrlichia equi and "HGE agent" as subjective synonyms of Ehrlichia phagocytophila. International Journal of Systematic and Evolutionary Microbiology 51: 21452165.

El-Ashker M et al., 2015. Molecular biological identification of Babesia, Theileria, and Anaplasma species in cattle in Egypt using PCR assays: Gene sequence analysis and a novel DNA microarray. Veterinary Parasitology 207: 329-334.

Estrada-Peña A and Salman M, 2013. Current limitations in the control and spread of ticks that affect livestock: A review. Agriculture 3: 221-235.

Fernandes-Rodríguez CJ et al., 2014. Subcell Biochemistry 74: 1-42: doi: 10.1007/978-94-007-7305-9_1.

Figueroa JV et al., 1998. Bovine Babesiosis and Anaplasmosis follow-up on cattle relocated in an endemic area for hemoparasitic diseases. Annals of the New York Academy of Sciences 849: 1-10.

Foil LD, 1989. Tabanids as vectors of disease agents. Parasitology Today 5: 88-96.

Futse JE et al., 2003. Transmission of Anaplasma marginale by Boophilus microplus: Retention of vector competence in the absence of vector-pathogen interaction. Journal of Clinical Microbiology 41: 38293834 .
Gale KR et al., 1996. Anaplasma marginale: Effect of challenge of cattle with varying doses of infected erythrocytes. International Journal for Parasitology 26: 1417-1420.

García-Ortíz MA et al., 200o. Anaplasma marginale: Diferentes grados de virulencia en dos aislados mexicanos. Veterinaria México 31: 157-16o.

Garry F, 2008. Miscellaneus infectious diseases. In: Divers TJ and Peek SF (editors) Rebhun's Diseases of Dairy Cattle. Second Edition, Saunders Elsevier.

Gibson W, 2002. Podría el verdadero Trypanosoma brucei rhodesiense dar un paso adelante? Trends in Parasitology 18: 486.

Gondard $\mathrm{M}$ et al., 2017. Ticks and tick-borne pathogens of the Caribbean: Current understanding and future directions for more comprehensive surveillance. Frontiers in Cellular and Infection Microbiology 7: 490.

Greiner M et al., 1997. Evaluation and comparison of antibody ELISAS for serodiagnosis of bovine Trypanosomosis. Veterinary Parasitology 73: 197205.

Hawkins JA et al., 1982. Mechanical transmission of Anaplasmosis by Tabanids (Diptera: Tabanidae). American Journal of Veterinary Research 43: 732-734.

Holland WG et al., 20o1. A comparative evaluation of parasitological tests and a PCR for Trypanosoma evansi diagnosis in experimentally infected water buffaloes. Veterinary Parasitology 97: 23-33.

Hopkins JS et al., 1998. Adaptation and validation of the antibody trapping ELISA using dried blood spots on filter paper, for epidemiological surveys of tsetse transmitted Trypanosomosis in cattle. Preventive Veterinary Medicine 37: 91-99.

Hornok S et al., 2008. Molecular identification of Anaplasma marginale and rickettsial endosymbionts in blood-sucking flies (Diptera: Tabanidae, Muscidae) and hard ticks (Acari: Ixodidae). Veterinary Parasitology 154: 354-359.

Isobe $\mathrm{T}$ et al., 2003. The transferrin receptor genes of Trypanosoma equiperdum are less diverse in their transferrin binding site than those of the broad-host range Trypanosoma brucei. Journal of Molecular Evolution 56: 377-386.

Issa R, 2019. Musca domestica acts as transport vector. Host. Bulletin of the National Research Centre. doi.org/10.1186/s42269-019-0111-o.

Jordan AM, 1976. Tse tse flies as vectors of trypanosomes. Veterinary Parasitology 2: 143-152.

Khamesipour F et al., 2018. A systematic review of human pathogens carried by the housefly (Musca domestica L.) Khamesipour et al. BMC Public Health doi.org/10.1186/s12889-018-5934-3.

Kocan KM et al., 2010. The natural history of Anaplasma marginale. Veterinary Parasitology 167: 95-107.

Kocan KM et al., 2004. Anaplasma marginale (Rickettsiales: Anaplasmataceae): Recent advances in defining host-pathogen adaptations of a tick-borne rickettsia. Parasitology 129: S285-S300. 
Kumar $\mathrm{N}$ et al., 2019. Molecular assessment of Anaplasma marginale in bovine and Rhipicephalus (Boophilus) microplus tick of endemic tribal belt of coastal South Gujarat, India. Acta Parasitologica Springer. https://doi.org/10.2478/s11686-019-00041-z.

Lohr CV et al., 2002. Specific expression of Anaplasma marginale major surface protein 2 salivary gland variants occurs in the midgut and is an early event during tick transmission. Infection and Immunity 70 : 114-120.

M'ghirbi Y et al., 2016. Anaplasma marginale and A. phagocytophilum in cattle in Tunisia. Parasites and Vectors 9: 556.

Madhav $\mathrm{M}$ et al., 2019. Pre-print. Complete genome assembly of the Wolbachia endosymbiont of the horn fly Haematobia irritans irritans: A supergroup A strain with multiple horizontally acquired cytoplasmic incompatibility genes. Biorxiv preprint doi: https://doi.org/10.1101/836908

Marangoni-Marana ER et al., 2009. Soroprevalência de Anaplasma marginale em bovinos da região CentroSul do estado do Paraná, Brasil, por um teste imunoenzimático competitivo utilizando proteína recombinante MSP5-PR1. Revista Brasileira de Parasitologia Veterinária 18(1): 20-26.

Mark F and Wiser, Tulane University 1999. Latest update January 24, 2020. http://www.tulane.edu/ wiser/ protozoology/notes/kinet.html\#chagas.

Mehlhorn H, 2015. Flies as vectors of parasites. Encyclopedia of Parasitology, Springer, Berlin, Heidelberg. https://doi.org/10.1007/978-3-642-277696_3881-1

Mercado A et al., 2011. Frequency of Anaplasma marginale (Theiler 1910) and Babesia sp in mestizo bovine Zebu, in the Municipality of Ixiamas county Abel Iturralde Department of The La Paz, Bolivia. Journal of Selva Andina Research Society 2: 13-23.

Noaman $\mathrm{V}$ et al., 2019. Molecular epidemiology and risk factors assessment of Anaplasma spp. on dairy cattle in southwest of Iran. Acta Veterinaria Eurasia 45: 3036.

Odeniran OP et al., 2018. Bovine and small ruminant African animal Trypanosomiasis in Nigeria-A review. Veterinary Parasitology: Regional Studies and Reports 13: 5-13. doi: 10.1016/j.vprsr.2018.03.001.

OIE, 2021. Information on aquatic and terrestrial animal diseases. OIE-Listed diseases, infections and infestations in force in 2021. https://www.oie.int/ en/animal-health-in-the-world/information-on-aqua tic-and-terrestrial-animal-diseases

Quiroz-Castañeda RE et al., 2016. Anaplasma marginale: Diversity, virulence, and vaccine landscape through a genomics approach. BioMedical Research International, article ID 9032085.

Reinbold JB et al., 2010. Comparison of iatrogenic transmission of Anaplasma marginale in Holstein steers via needle and needle-free injection techniques. American Journal of Veterinary Research 71: 1178-1188.

Ribeiro-Gasparini $\mathrm{M}$ et al., 2013. Immune response of calves inoculated with proteins of Anaplasma marginale bound to an immunostimulant complex. Revista Brasileira de Parasitologia Veterinária 22(2): 253-259.

Ringo AE et al., 2020. Molecular detection and characterization of tick-borne haemoparasites among cattle on Zanzibar Island, Tanzania. Acta Tropica 211: 105598; doi: https://doi.org/10.1016/j.actatropica.2020.105598.

Ristic M, 1981. Anaplasmosis. In: Ristic M and McIntyre I (editors), Diseases of Cattle in the Tropics. Current Topics in Veterinary Medicine and Animal Science. Volume 6. Springer, Dordrecht. Pp: 327-344.

Rjeibi MR et al., 2017. Molecular survey and genetic characterization of Anaplasma centrale, A. marginale and $A$. bovis in cattle from Algeria. Transboundary and Emerging Diseases 65(2): 456-464.

Roche, 2004. Situacion actual de la tripanosomiasis humana africana. ENF Emergency Educational Grants 2004: 91-97.

Rodhain F, 2015. Insects as vectors: Systematics and biology. Revue Scientifique et Technique (Office International of Epizootics) 34: 83-96.

Rodríguez CSD et al., 2008. Anaplasma marginale Yucatán (Mexico) Strain. Assessment of low virulence and potential use as a live vaccine. Annals of the New York Academy of Sciences 1149: 98-102.

Rodríguez SD et al., 200o. Anaplasma marginale inactivated vaccine: Dose titration against a homologous challenge. Comparative Immunology, Microbiology and Infectious Diseases 23: 239-252.

Rodríguez SD et al., 2009. Molecular epidemiology of bovine Anaplasmosis with a particular focus in Mexico. Infection, Genetics and Evolution 9: 10921101.

Rodríguez-Gallegos CE and Acosta-Rodríguez, 2011. Genetic and environmental factors influencing the resistance of terminal cross calves to tick Rhipicephalus (Boophilus) microplus and horn fly Haematobia irritans. Tropical and Subtropical Agroecosystems 13: 437-444.

Rodríguez-Vivas RI et al., 2006. Manual técnico para el control de garrapatas en el ganado bovino. National Center for Disciplinary Research in Veterinary Parasitology INIFAP, Technical publication No. 4, october.

Rogers DJ et al., 1994. Tse tse flies and their control. Revue Scientifique et Technique (International Office of Epizootics) 13: 1075-1124.

Schofield CJ and Maudlin I, 20o1. Trypanosomiasis control. International Journal of Parasitology 31: 614619.

Scholl PJ and Broce AB, 2003. Stomoxys calcitrans - the stable fly (Mosca de los establos): Biology, ecology, economic importance and control. In: V International Seminar in Animal Parasitology. October 1-3, Mérida, Yucatán, México pp: 177-182.

Scoles GA et al., 2005. Relative efficiency of biological transmission of Anaplasma marginale (Rickettsiales: Anaplasmataceae) by Dermacentor andersoni (Acari: 
Ixodidae) compared with mechanical transmission by Stomoxys calcitrans (Diptera: Muscidae). Journal of Medical Entomology 42: 668-675.

Scoles GA et al., 2008. Comparison of the efficiency of biological transmission of Anaplasma marginale (Rickettsiales: Anaplasmataceae) by Dermacentor andersoni stiles (Acari: Ixodidae) with mechanical transmission by the horse fly, Tabanus fuscicostatus hine (Diptera: Muscidae). Journal of Medical Entomology 45: 109-114.

Seo $\mathrm{M}$ et al., 2018. Differential identification of Anaplasma in cattle and potential of cattle to serve as reservoirs of Anaplasma capra, an emerging tickborne zoonotic pathogen. Veterinary Microbiology 226: 15-22.

Silva RAMS et al., 1995. Trypanosomosis outbreaks due to Trypanosoma evansi in the Pantanal, Brazil. Revue d Élevage et de Médecine Veterinaire des Pays Tropicaus 48: 315-319.

Simarro PP et al., 2013. Diversity of human African Trypanosomiasis epidemiological settings requires ne-tuning control strategies to facilitate disease elimination. Research and Reports in Tropical Medicine 4: 1-6.

Spare MR et al., 2020. Bovine Anaplasmosis herd prevalence and management practices as risk factors associated with herd disease status. Veterinary Parasitology 277(Supplement): 100021.

Sprong $\mathrm{H}$ et al., 2019. Detection of pathogens in Dermacentor reticulatus in northwestern Europe: evaluation of a highthroughput array. Heliyon 5: eo1270.

Swift BL and Thomas GM, 1983. Bovine Anaplasmosis: Elimination of the carrier state with injectable longacting oxytetracycline. Journal of the American Veterinary Medical Association 183: 63-65.

Tana-Hernández L et al., 2017. PCR-diagnosis of Anaplasma marginale in cattle populations of Ecuador and its molecular identification through sequencing of ribosomal $16 \mathrm{~S}$ fragments. BMC Veterinary Research 13: 392.

Theiler A, 1910a. Gall sickness of South Africa (Anaplasmosis of cattle). Journal of Comparative Pathology and Therapeutics 23: 98-115.

Theiler A 1910b. Anaplasma marginale (gen. and spec. nov). The marginal points in the blood of cattle suffering from a specific disease. In: Theiler, A. (editor), Report of the Government on Veterinary
Bacteriology in Transvaal. Department of Agriculture, South Africa, 1908-1909, pp: 7-64.

Theiler A, 1911. Further investigations into Anaplasmosis of South African cattle. In: 1st Report of the Director of Veterinary Research. Department of Agriculture of the Union of South Africa, pp: 7-48.

Torioni de Echaide S et al., 1998. Detection of cattle naturally infected with Anaplasma marginale in a region of endemicity by nested PCR and a competitive enzyme-linked immunosorbent assay using recombinant major surface protein 5. Journal of Clinical Microbiology 36: 777-782.

Torres L et al., 2012. Identification of microorganisms in partially fed female horn flies, Haematobia irritans. Parasitology Research 111: 1391-1395.

Vega LEO et al., 2007. Anaplasma marginale field challenge: Protection by an inactivated immunogen that shares partial sequence of mspi alpha variable region with the challenge strain. Vaccine 25: 519-525.

Whitlock BJ, 2014. Seroprevalence of bovine Anaplasmosis in the southern US. The American Association of Bovine Practitioners Proceedings. Consult in http://foundation.aabp.org/research_proposal/2012_g rant_Whitlock.pdf.

Yunik MEM et al., 2016. Active surveillance of Anaplasma marginale in populations of arthropod vectors (Acari: Ixodidae; Diptera: Tabanidae) during and after an outbreak of bovine Anaplasmosis in southern Manitoba, Canada. The Canadian Journal of Veterinary Research 80: 171-174.

Zabel TA and Agusto FB, 2018. Transmission dynamics of Bovine Anaplasmosis in a cattle herd, Hindawi. Interdisciplinary Perspectives on Infectious Diseases 2018: Article ID 4373981.

Zhou Z et al., 2019. Molecular epidemiology and risk factors of Anaplasma spp., Babesia spp. and Theileria spp. infection in cattle in Chongqing, China. PLoS One 14(7): eo215585.

Zhyldyz A et al., 2019. Epidemiological survey of Anaplasma marginale in cattle and buffalo in Sri Lanka. Journal of Veterinary Medical Science 81: 16011605.

Zumpt F, 1973. The Stomoxyine Biting Flies of the World. Gustav Fischer Verlag. Stuttgart. pp: 137-152.

Zwart D, 1985. Haemoparisitic diseases of bovines. Revue Scientifique et Technique (International Office of Epizootics) 4: 447-458. 